\title{
Cerebrospinal fluid pressure
}

\author{
K. C. BRADLEY \\ From the Department of Anatomy, University of Melbourne, Victoria, Australia
}

SUMMARY The cerebrospinal fluid pressure at the foramen of Monro in man in the recumbent position is less than $100 \mathrm{~mm}$ water relative to atmospheric pressure. The oscillations in the pressure wave due to respiration and cardiac pulsation vary with the actual pressure and increase as the overall pressure rises. In man lying horizontally the oscillation at the foramen of Monro is usually less than $50 \mathrm{~mm}$ water pressure, of which the cardiac component is about $15 \mathrm{~mm}$ and the respiratory component $35 \mathrm{~mm}$ water pressure. The fluid pressure within the cranial cavity is not uniform. In the recumbent face upwards position the pressure at the frontal pole is close to atmospheric or slightly subatmospheric but at the occipital pole is of the order of 160 to $190 \mathrm{~mm}$ water pressure. Examples are given showing the effect of posture on cerebrospinal fluid pressures in man and in the goat. The concentration of arachnoid granulations and venous lacunae near the vertex and the pressures in this region are discussed. The need for more precise methods of pressure measurement in the superior sagittal sinus is outlined by citing the Pitot tube. Pressure studies on patients with presenile dementia and dilated cerebral ventricles are reported.

As early as 1881 , Falkenheim and Naunyn (1887) designed experiments to measure normal cerebrospinal fluid pressures. Weed (1914-15) observed that the greatest concentration of the arachnoid villi relative to the superior sagittal sinus was over the vertex in the region of the motor cortex - a region where there was a concentration of cerebral veins entering the superior sagittal sinus. He found no histological evidence for valves in the arachnoid villi, but one of his conclusions was as follows: 'The chief method of return of cerebrospinal fluid to the general circulation is by a process of filtration through arachnoid villi into the great sinuses.' In this regard an important recent contribution was that of Welch and Friedman (1960). They demonstrated tiny tubules in the arachnoid villi and granulations.

There is a good deal of confusion concerning values of cerebrospinal fluid pressure and also there are several conflicting reports about the relationship between this pressure and venous pressure. Indeed in certain conditions as the intracranial pressure rises the pressure in the superior sagittal sinus may fall (Wright, 1938). Another source of confusion stems from statements about the fluid pressure without reference to the precise site at which it is measured.

${ }^{1}$ This work was supported by the National Health and Medical Research Council of Australia
For example, it can be shown that the fluid pressure, say, in the subarachnoid space near the frontal pole of the brain is much lower than that near the occipital pole in a subject lying face upwards. Since it is likely that a pressure difference of about $60 \mathrm{~mm}$ of water between the superior sagittal sinus and the adjacent subarachnoid space will allow drainage of cerebrospinal fluid, small pressure changes from area to area within the cranial cavity assume importance. This fact was demonstrated in the monkey by Welch and Friedman (1960).

Thomas and Kerr (1965) investigated in cats by electron microscope techniques the distribution and absorption of colloidal particles from the subarachnoid space. Their findings indicate a much greater permeability of the vessel wall of the capillary endothelium of arachnoid villi than that of the cortical capillaries. Cytoplasmic organelles containing colloidal gold were present in the vessels of the villi but never in cortical capillaries. These workers suggest a specialization of vessels in the arachnoid villi, whereas Welch and Friedman (1960) provide evidence for a valvular action of arachnoid tubules.

Until recently the pressure had been recorded usually by introducing a needle into the subarachnoid space, commonly in the lumbar spinal theca and frequently in the cisterna magna. For more precise measurements it is necessary to ensure that no 
fluid escapes from the ventricles or subarachnoid spaces. A pressure transducer meets these requirements.

Pressure recordings in this study have been made on normal and abnormal human subjects and on animals. Some human subjects showed intracranial pathology such as hydrocephalus, subdural haematoma, and tumour, but others showed no abnormality and formed the basis for the preparation of normal pressure records.

\section{APPARATUS}

1. PRessure TRANSDUCERS Hewlett Packard models in the 267 and 268 series and Statham models P23 and 1280 were used in these tests. The transducers were connected single ended to the brain ventricle or subarachnoid space or to venous channels with the other input at atmospheric pressure.

2. RECORDING DEVICES Recordings were made with a Philips ink and a Hewlett Packard 7712B two channel thermal recording system.

\section{METHOD}

A fine bore rubber or plastic catheter usually about no. 8 Fr. gauge was introduced either into a lateral ventricle of the brain or in some cases into the cisterna magna. In the human subjects either under local or general anaesthesia a small burr hole was made at the coronal suture at $3 \mathrm{~cm}$ lateral to the mid-sagittal plane. The catheter with a stylet was gradually advanced until it could be felt to enter the roof of the lateral ventricle. The stylet was then removed and the outer end of the catheter was quickly sealed with a metal plug in an adaptor. If the soft catheter is now gently advanced a short distance its tip will be found in most cases to lie close to the interventricular foramen of Monro. It has been possible therefore to make a series of recordings of pressures in the vicinity of the foramen of Monro. The position of the catheter was confirmed in each case by radiography after the introduction of a small quantity of opaque dye.

\section{RESULTS}

Figure 1 shows the tip of the tube (size 8 Fr.) with its terminal opening in the interventricular foramen. The transducer measures the pressure difference between the cerebrospinal fluid and the atmosphere. It is important at all times to have a reference point in the cerebrospinal fluid the level of which may be referred to that of the transducer diaphragm. Let us suppose that the transducer diaphragm is on the same level as the brain at the point of exit of the emerging catheter and a pressure of $\mathrm{p} \mathrm{mm}$ of water is indicated If the transducer is lowered a distance of $\mathrm{x} \mathrm{mm}$ the pressure indicated will be $p+x \mathrm{~mm}$ of water. It is clear that, unless the level of the transducer relative
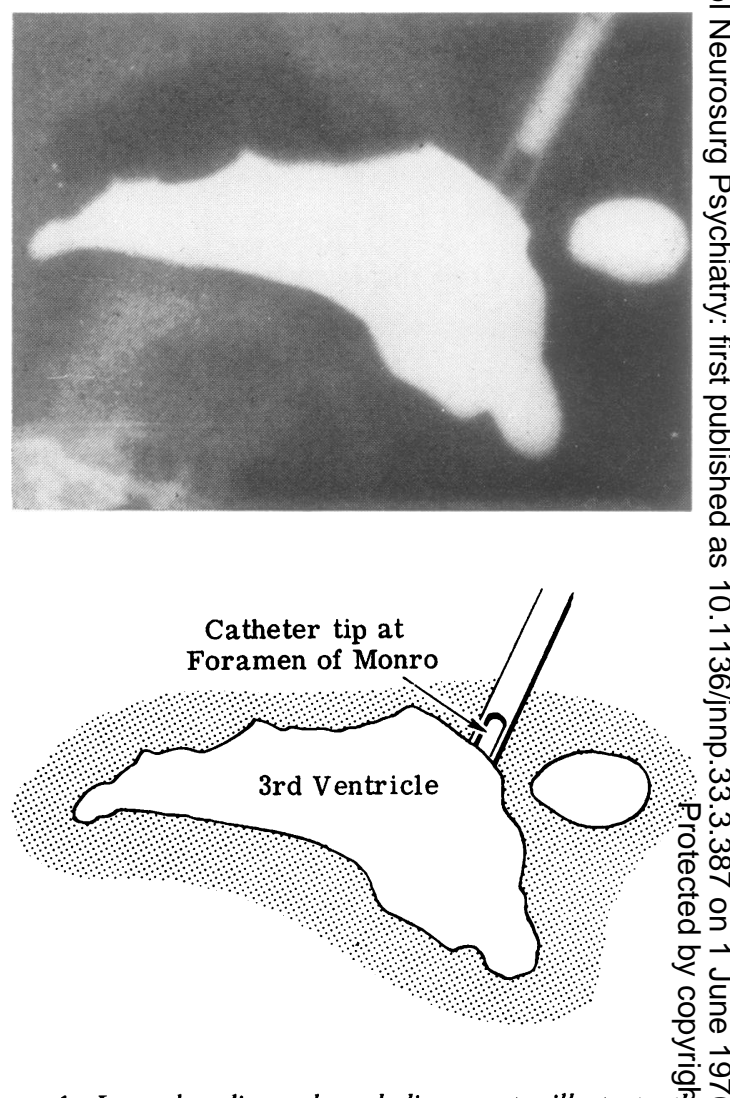

FIG. 1. Lateral radiograph and diagram to illustrate the. position of the catheter used for pressure recordings fromthe foramen of Monro in man.

to some point in the area of measurement is known, the results are without meaning.

In human subjects lying face upwards the brain catheter usually sloped downwards from the brain surface at the coronal suture to its terminal opening near the foramen of Monro. The difference in verticalo height was usually 20 to $30 \mathrm{~mm}$. A recording then of say $+30 \mathrm{~mm}$ of water pressure at the brain surface in the parasagittal region beneath the coronal suture? would mean that the pressure at the interventricular $\frac{}{3}$ foramen of Monro would be of the order of +50 to $+60 \mathrm{~mm}$ of water relative to atmospheric pressure. In the goat, catheters were inserted into the lateral ventricles of the brain and also into the cisterna magna.

THE NORMAL PRESSURE The normal pressure refers to the curve of pressure which fluctuates between a maximum and minimum value and in which can be seen pulsations mainly due to respiration and the 
cardiac pulse. This is illustrated in Fig. 2, in which a pressure tracing from the lateral ventricle of the human brain has been expanded to show the cardiac and respiratory pulses. The posture of the subject must be recorded since the pressures at a particular intracranial site will change from positive values when the body is tilted head downwards to negative values (compared with atmospheric pressure) when the body is tilted head upwards. Masserman (1934) gives average values of about $150 \mathrm{~mm}$ of saline from the lumbar theca in the lateral recumbent position. Spina-Franca (1963) (quoted by Davson) found a mean value of $119 \mathrm{~mm}$ of saline from the cisterna magna in the lateral recumbent position. Gilland (1969) found an average cerebrospinal fluid pressure of $144 \mathrm{~mm} \mathrm{H}_{2} \mathrm{O}$ at lumbar puncture in the lateral recumbent position using an isometric strain gauge technique.

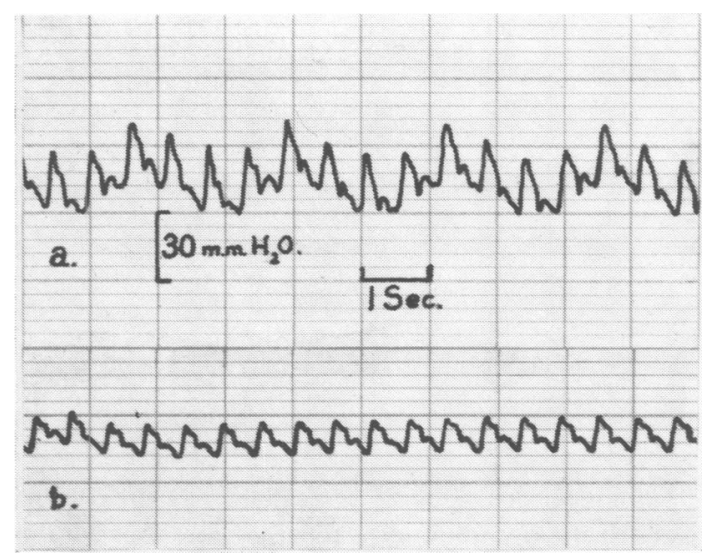

FIG. 2. Pressure variations, associated with pulse and respiration, from the lateral cerebral ventricle in man. (a) pulse and respiration, (b) pulse (during apnoea).

In the goat the following are typical findings. Under general anaesthesia the pressure in the lateral ventricle of the brain (with the animal lying on its side) fluctuated between about 120 and $190 \mathrm{~mm}$ water. In apnoea this fluctuation (previously $70 \mathrm{~mm}$ water) dropped to about $20 \mathrm{~mm}$ water with the same minimum value of $120 \mathrm{~mm}$ water and the maximum reduced to $140 \mathrm{~mm}$ water.

An example is given from the measurements of cerebrospinal fluid pressure at the interventricular foramen of Monro in a 63-year-old man (Fig. 3). The diaphragm of the pressure transducer was level with the burr hole at the coronal suture and the foramen of Monro was $30 \mathrm{~mm}$ below this level. The subject was recumbent and the pressure recording fluctuated between 25 and $50 \mathrm{~mm}$ water. Allowing for the hydrostatic pressure in the catheter, this gave a value at the foramen of Monro of 55 to $80 \mathrm{~mm}$ water pressure above atmospheric pressure. Figure 3 is based on the actual measurement of fluid pressures at the foramen of Monro with a calculation of the pressure at other areas of the cranial cavity allowing for the hydrostatic pressure head. The brain and the cerebrospinal fluid have specific gravities slightly greater than water namely 1.040 and 1.003 (ventricle) respectively. One could expect a pressure difference of about $180 \mathrm{~mm}$ water between the frontal and occipital lobes of the brain in the recumbent position.

There tends to be a high concentration of arachnoid granulations adjacent to the superior sagittal sinus extending posteriorly from the central region of the brain. A most important study is that of Cutler, Page, Galicich, and Watters (1968). Using perfusion techniques in children, they found that no absorption of cerebrospinal fluid occurred below a ventricular pressure (with the patient in a horizontal position) of $68 \mathrm{~mm}$ cerebrospinal fluid. The pressure at which formation and absorption rates were equal was of the order of $112 \mathrm{~mm}$ cerebrospinal fluid pressure. They concluded that this value $(112 \mathrm{~mm}$ cerebrospinal fluid) represents the average physiological pressure within the cerebrospinal fluid compartment in patients in the horizontal position.

In the subject illustrated in Fig. 3 the pressure of fluid at about the centre of the area of arachnoid granulations near the vertex would fluctuate from 95 to $120 \mathrm{~mm}$ water above atmospheric pressure. It has been shown (Welch and Friedman, 1960) that a differential pressure of $60 \mathrm{~mm}$ water is sufficient to allow fluid to pass through the arachnoid granulations in an isolated portion of monkey meninges. The measurements of cerebrospinal fluid pressure in the recumbent adult human in this study agree closely with those of Cutler et al. (1968). It would seem likely that in the human in the recumbent position conditions are satisfactory for drainage to occur from this concentrated area of granulations and also for a balance to exist between rates of formation and absorption of cerebrospinal fluid. Conditions are entirely different in the erect position because the cerebrospinal fluid pressure near the arachnoid granulations over the vertex will be much lower and even subatmospheric. However, the superior sagittal sinus pressure also falls. Whether absorption continues in this region in the erect position or increases in other areas is not clear. The rate of drainage of cerebrospinal fluid will vary from time to time at any particular area depending on the local conditions of the pressure differences between the fluid and the adjacent venous sinus. There is a linear 


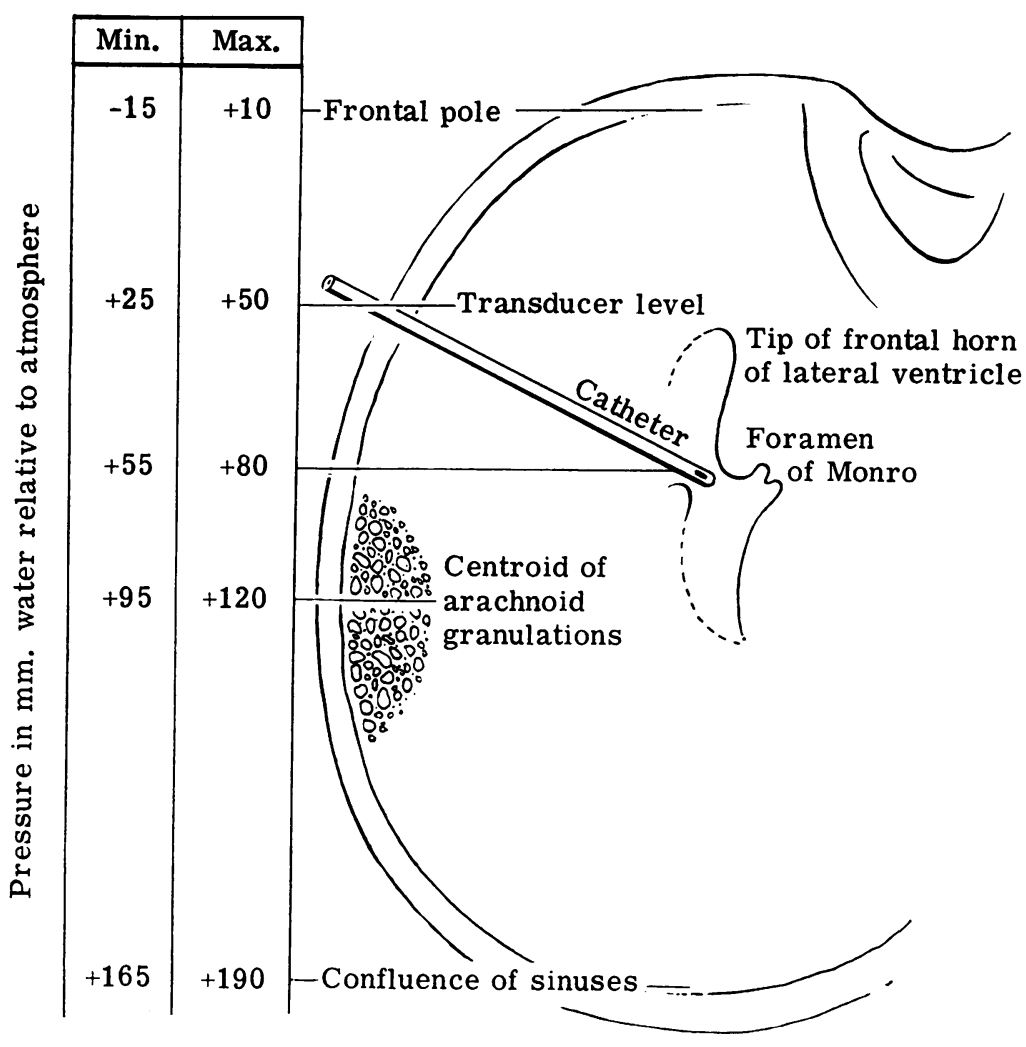

FIG. 3. Diagram illustrating the cerebrospinal fluid pressures at various sites within the cranial cavity.

relationship between the rate of absorption of cerebrospinal fluid and ventricular pressure in the recumbent position in children in the range $68 \mathrm{~mm}$ cerebrospinal fluid (opening pressure) to $250 \mathrm{~mm}$ cerebrospinal fluid as recorded by Cutler et al. (1968).

The following test illustrates the pressure variation in various head positions. The subject, a 57-year-old man, presented as a psychiatric problem and during the course of clinical investigations pressure recordings were taken of the cerebrospinal fluid. The subject was recumbent and under local anaesthesia a catheter was inserted into a lateral ventricle via a burr hole at the coronal suture. A subsequent radiograph showed the catheter tip at the foramen of Monro.

The fluid pressure at one point on the brain surface (at the coronal suture) increased by approximately $120 \mathrm{~mm}$ water when the head was moved from a flexed to an extended position (Fig. 4).

Body movement-postural changes Tilting of the body produces considerable variations in cerebrospinal fluid pressure. The following test was done on a patient under general anaesthesia with artificialo respiration via an endotracheal tube, but similar recordings are obtained in the conscious patient.o This test showed that the minimum pressure at theo brain surface at the coronal suture changes from $\propto$ approximately $-20 \mathrm{~mm}$ water to $+150 \mathrm{~mm}$ water $\overrightarrow{\overrightarrow{0}}$ when the subject was moved from an inclination of 3 $25^{\circ}$ above horizontal to $25^{\circ}$ below horizontal (Fig. 5). Similar effects from tilting the body occur in animals. Considerable pressure changes occur for example in the cisterna magna of the goat. Figure $6 \overline{0}$ summarizes the pressure changes with body tilting 0 and the pulsation in each position. The lowest 3 . pressure reading was $-100 \mathrm{~mm}$ water and highest $\delta$ $+370 \mathrm{~mm}$ water. Weed, Flexner, and Clark (1932) found in the dog a pressure maximum in the cisterna 0 magna of about $+380 \mathrm{~mm}$ water and a minimum of $-100 \mathrm{~mm}$ water between vertical head-down and vertical tail-down positions. Davson (1967) refers to Masserman's experiments on lumbar theca fluid or pressures and the effect of tilting the body. The N increase in lumbar fluid pressure in man, from the N horizontal to the sitting position, is much less than 
mm. $\mathrm{H}_{2} 0$ pressure

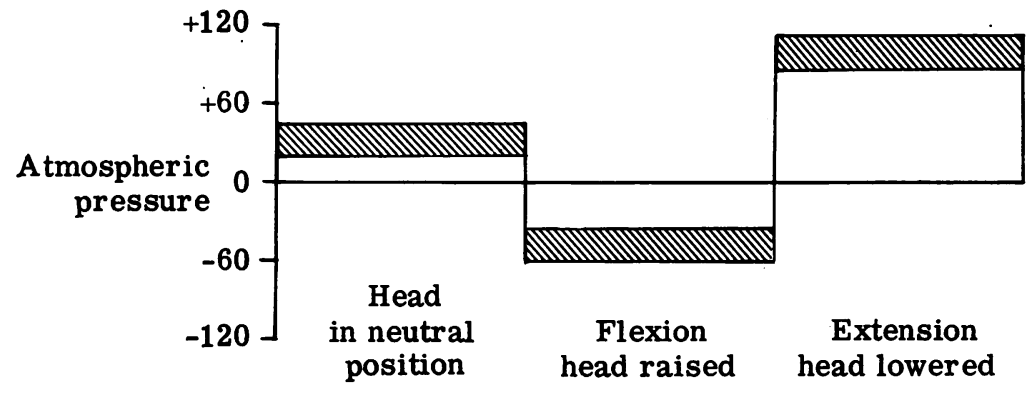

FIG. 4. Cerebrospinal fluid pressure variations at the brain surface at the coronal suture in the recumbent subject in various head positions.

$\underline{\mathrm{mm} . \mathrm{H}_{2}}{ }^{0}$ pressure

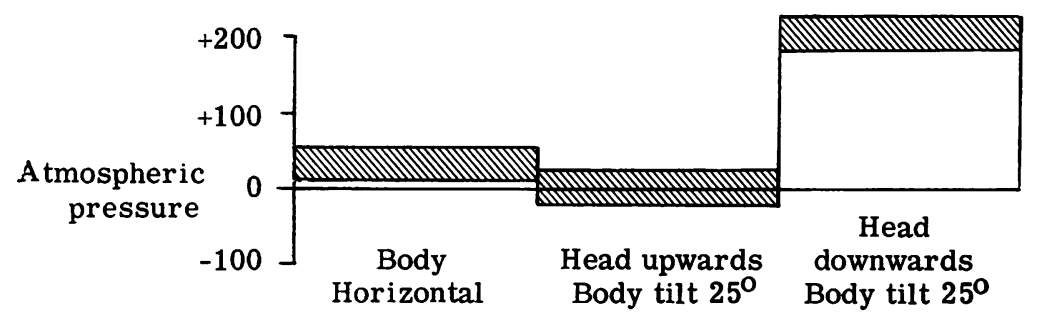

FIG. 5. Cerebrospinal fluid pressure variations at the brain surface beneath the coronal suture in man and associated with tilting of the body.

C.S. F. pressure $\mathrm{mm}$. water

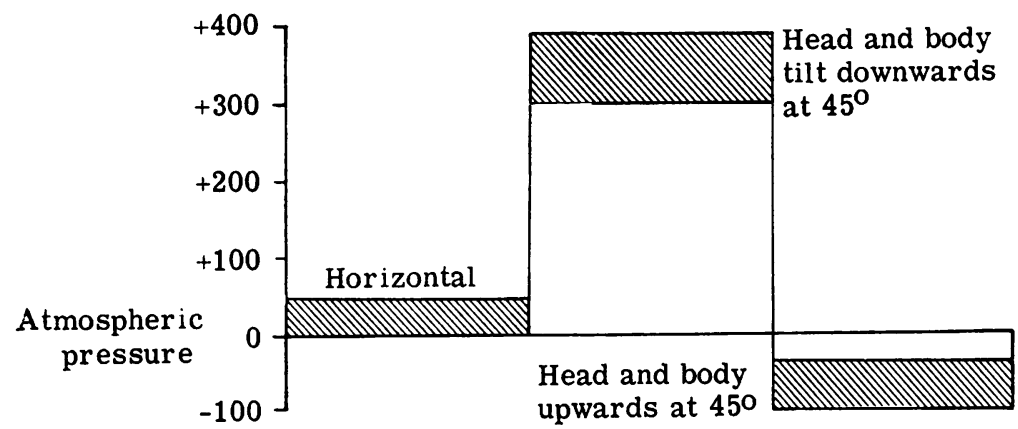

FIG. 6. Cerebrospinal fluid pressure variations in the cisterna magna of the goat associated with tilting of the body. one would expect, taking into account the difference in vertical height between the head and the lumbar region.

Many workers have suggested that there is an elastic component which modifies what otherwise would be a large fluctuation in cerebrospinal pressure with change of posture. However, both venous sinus pressure and intracranial cerebrospinal fluid pressures change with posture and in both animals and man the fluid pressure at the highest point in the cranial cavity in the vertical position is subatmospheric. The subatmospheric pressure often of the order of $-100 \mathrm{~mm}$ water appears to be the factor which partly neutralizes the hydrostatic pressure, so that in the sitting position one would expect a manometer column of fluid to reach no higher than the cisterna magna.

The superior sagittal sinus may be regarded as the tube of a suction pump, the pump chamber being the right atrium of the heart. The cerebrospinal fluid pressure must be lower than that in the thin-walled adjacent cerebral veins but normally the pressure in 
the subarachnoid fluid and in the subdural veins must exceed that in the rather rigid walled superior sagittal sinus. It seems likely, in the conditions in which children were tested by Cutler et al. (1968), that at some point along the superior sagittal sinus, with the subject recumbent, the pressure in the sinus was lower than $68 \mathrm{~mm}$ cerebrospinal fluid, which was the opening ventricular pressure above which absorption occurred.

A cerebral vein is thin walled in the subarachnoid space but in its passage into the sinus there is a change, so that for a short distance as it traverses the subdural space the dorsal wall is thick and firm due to the dura mater while the wall near the brain surface is still thin walled. The terminal portion of the vein has a firm circumference of dura mater and enters the sinus via a slit-like opening with a sharp crescentic edge of dura mater. While some cerebral veins enter the sinus in a direction opposite to the blood flow in the sinus, many veins curve through $180^{\circ}$ so that they actually discharge blood in the direction of the sinus flow. Wright (1938) examined the effect on the intracranial vasculature of raising the intracranial pressure in dogs. When the pressure of the cerebrospinal fluid was increased no definite collapse of veins occurred except near the sinuses. At $\frac{\text { o }}{Z}$ this site a cuff constriction appeared with intermittent $\mathbb{\Phi}$ emptying into the sinuses. The emptying occurred just after inspiration. Wright (1938) also observed ${ }^{\text {कn }}$ that the sagittal sinus does not collapse as the intracranial pressure rises but, if incised, it will 0 collapse but the adjacent subarachnoid veins remain full and distended to the sinus edge. $\mathrm{He}$ also noted the gradual fall of pressure in the sagittal sinus as the intracranial pressure was increased, a fall which reached $-60 \mathrm{~mm}$ of water pressure relative to atmospheric pressure.

The following pressure study on an adult female with pre-senile dementia and somewhat dilated ventricles is of interest (Fig. 7).

A no. 8 French catheter was introduced into the right lateral ventricle via a burr hole at the coronal ${ }^{\text {os }}$ suture and $3 \mathrm{~cm}$ from the midline. The tip of the $\vec{O}$ catheter was subsequently shown to be immediately above the interventricular foramen of Monro. The $\vec{\sigma}$ patient was under general anaesthesia with an intratracheal tube and with the anaesthetic administered at an intrathoracic pressure fluctuating from 0-20 $\mathrm{cm}$ of water pressure. At the commencement of the $\omega$ test the patient was lying face upwards and hor $\omega$

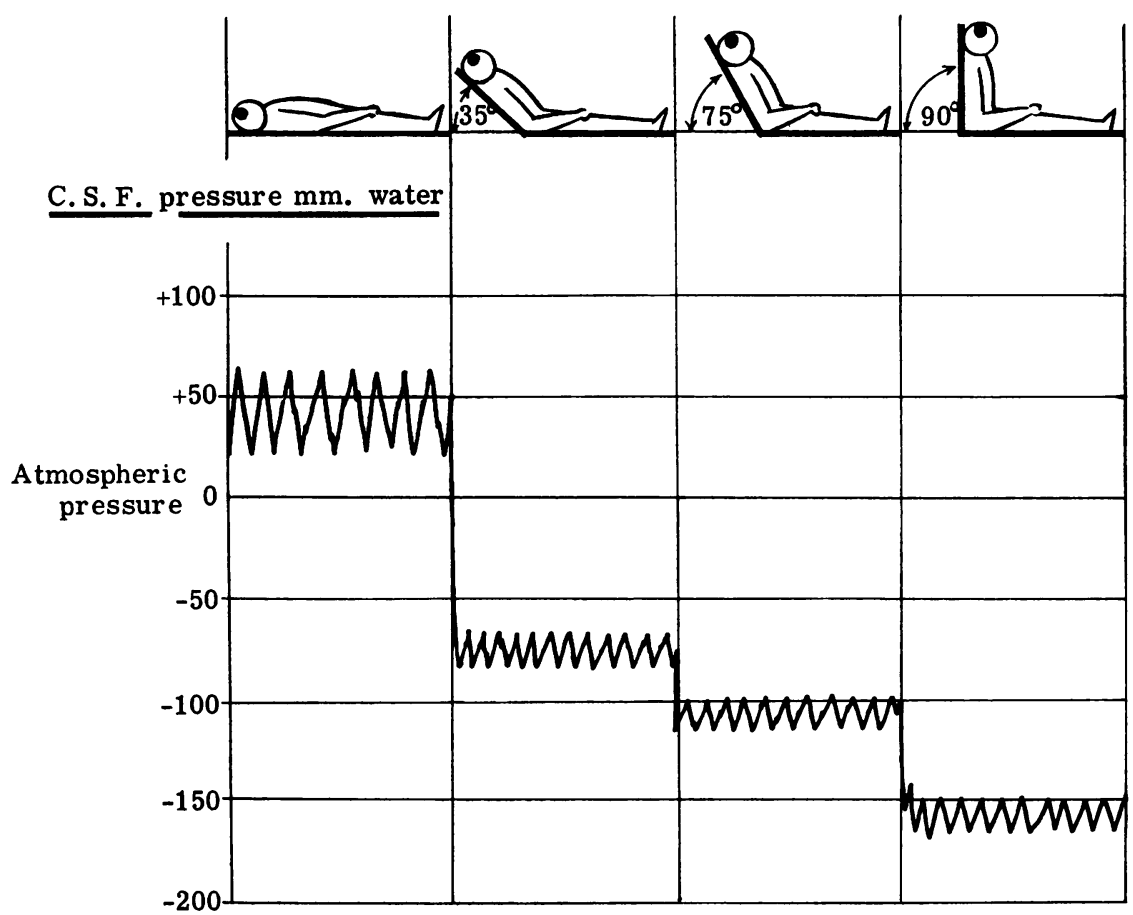

FIG. 7. Effect of posture on cerebrospinal pressure in a patient with presenile dementia and dilated cerebral ventricles. 
zontal, and the diaphragm of the pressure transducer was level with the brain surface at the point where the catheter emerged. The first recording showed nothing remarkable in that the magnitude and the variation in pressure were within normal limits, normally fluctuating between approximately 20 and $50 \mathrm{~mm}$ of water pressure above atmospheric.

In the next phase of the recording the patient was partly sat up to an angle of about $35^{\circ}$ above the horizontal. The transducer was again levelled with the same point on the brain surface and the pressure was seen to drop markedly to a mean of $-75 \mathrm{~mm}$ of water. It could also be seen that the fluctuation in pressure was smaller than previously and only of the order of about $15 \mathrm{~mm}$ of water. The patient was then sat up at $75^{\circ}$ and the pressure fell to a mean of $-110 \mathrm{~mm}$ of water.

In the fourth segment of the recording the patient was sitting upright and looking forwards. The transducer was again levelled with the brain surface and in this position was approximately level with the highest point of the brain at the vertex. There was a further drop in pressure so that this was now recording as low as $-165 \mathrm{~mm}$ of water. At this time the intrathoracic pressure was oscillating between 0 and $20 \mathrm{~cm}$ of water and the systolic blood pressure which had been $110 \mathrm{~mm}$ of mercury in the horizontal position had risen to $140 \mathrm{~mm}$ of mercury in the sitting up position. It seems, then, that if fluid were to transfer from the subarachnoid space to the superior sagittal sinus near the vertex in the sitting up position the venous pressure at that site would need to be $-200 \mathrm{~mm}$ of water in relationship to the atmospheric pressure or even lower. Indeed the fluid pressure was so low in the sitting up position that one wondered whether, in this patient, fluid transfer could occur in the region of the vertex into the superior sagittal sinus. It may be that these abnormal pressure characteristics and the dilated ventricles are interrelated.

THE PULSES The fluid pressure exhibits both cardiac and respiratory variations and both the pulse and respiratory rates can be counted on a tracing of pressure in the lateral ventricle of the brain. Figure 2 is a typical tracing of pressure in the lateral ventricle of the human brain. The origin of the cardiac pulse in the cerebrospinal fluid has been attributed by some to the choroid plexus. However, there is no doubt that the cerebral and spinal arteries as a whole are important in this regard (Dunbar, Guthrie, and Karpell, 1966). These workers have shown that the fluid pulse in any area of the brain ventricles or subarachnoid space correlates well with the arterial pulse. The ventricular and carotid pulse waves have the same characteristics. The upper tracing in Fig. 2 shows the fluctuations due to the combined cardiac and respiratory effects and in the lower tracing the cardiac pulsation is seen during apnoea. The fluid pressure tracings from the goat brain ventricle or cisterna magna show similar characteristics to those of the human and reflect the arterial pulse. In the test referred to in Fig. 2 the pressure variation due to the cardiac pulse was $15 \mathrm{~mm}$ water and the combined cardiac and respiratory change was $45 \mathrm{~mm}$ water pressure. O'Connell (1943) also found a cardiac variation of $15 \mathrm{~mm}$ saline and a respiratory variation of $35 \mathrm{~mm}$ saline (using a wide bore needle and manometer). Goldensohn, Whitehead, Parry, Spencer, Grover, and Draper (1951) recorded similar findings from the lateral ventricle of the dog brain. An increase in the cardiac and the respiratory pulsations occurs with an increase in the cerebrospinal fluid pressure whatever the cause of the overall rise in intracranial pressure. In one test on a conscious patient the pressures were measured in the lateral ventricle of the brain in the recumbent and tilted head down position $\left(25^{\circ}\right)$. In the recumbent position the pulsation was $35 \mathrm{~mm}$ water ( 0 to 35 ) and when tilted head downwards at $25^{\circ}$ the pulsation increased to $55 \mathrm{~mm}$ water (145 to $200 \mathrm{~mm})$. In pathological states where the cerebrospinal fluid pressure is high, the amplitude of the combined cardiac and respiratory pulses may be $100 \mathrm{~mm}$ water pressure.

Respiratory pulse and fluid pressure The respiratory pulse is closely linked to the intrathoracic pressure in that as the intrathoracic pressure increases the fluid pressure rises and the oscillation becomes greater. This is shown in Table 1 where the intrathoracic pressure was varied during endotracheal anaesthesia in the goat. A pressure transducer was connected to a catheter in the cisterna magna. The method of ventilation during anaesthesia is clearly of great importance in relation to fluid pressures.

Loss of cerebrospinal fluid A slow drip of fluid from a brain ventricle can be recorded with a sensitive

TABLE 1

CEREBROSPINAL FLUID AND THORACIC PRESSURES IN GOAT (IN HORIZONTAL POSITION ON SIDE)

\begin{tabular}{cc}
\hline $\begin{array}{c}\text { Intratracheal pressure } \\
(\mathrm{mm} \mathrm{Hg})\end{array}$ & $\begin{array}{c}\text { Cisterna magna pressure } \\
\text { relative to atmospheric } \\
\text { pressure } \\
\left(\mathrm{mm} \mathrm{H}_{2} \mathrm{O}\right)\end{array}$ \\
\hline+10 to +40 & +55 to +100 \\
+4 to +28 & +30 to +75 \\
0 to +20 & 0 to +45 \\
-4 to +18 & 0 to +10 \\
apnoea & 0 to +10 \\
\hline
\end{tabular}


transducer. This will produce a wave with an amplitude of 2 to $3 \mathrm{~mm}$ water pressure and reminds one that this is a remarkably dynamic system.

The drainage mechanism The villi and granulations of the arachnoid are formed as invaginations into the dural sinuses and into the venous lacunae. They are especially well developed in the parietal region but appear also in the frontal and occipital regions near the superior sagittal sinus. Other venous sinuses may have venous lacunae associated with them but these are much smaller than those over the vertex. The venous lacunae communicate at their lateral borders with the middle meningeal venous sinuses as described by Clarke (1920) and with the lateral wall of the sinus by either a large oval or often several tiny circular openings. The arachnoidal granulations are grouped in at least two ways in relation to the superior sagittal sinus. One group projects directly into the superior sagittal sinus either as single granulations or over a wide area. The other group is enclosed in a cave of dura mater with interlacing bands of dura intersecting the cavity.

In the recumbent position the pressure at the interventricular foramen is commonly of the order of $80 \mathrm{~mm} \mathrm{H}_{2} \mathrm{O}$ maximum above atmospheric pressure. The pressure of cerebrospinal fluid near the superior sagittal sinus will vary from point to point along its course being low in the frontal region and increasing towards the confluence of the sinuses (in the recumbent position). With the subject lying horizontal and face upwards, conditions for the transfer of cerebrospinal fluid to the sinus would appear to be unfavourable at or above the horizontal level of the interventricular foramen but below this level the pressure of the cerebrospinal fluid is higher and in the parietal region there is a large concentration of arachnoid granulations favouring fluid transfer to the sinus (Fig. 3). In the erect position the cerebrospinal fluid pressure at the arachnoid granulations near the vertex is subatmospheric and approximately $70 \mathrm{~mm}$. $\mathrm{H}_{2} \mathrm{O}$ pressure below that at the interventricular foramen. Actual pressures at the coronal suture level near the superior sagittal sinus measured in a conscious human subject are shown in Table 2.

The superior sagittal sinus pressure will also rise or fall depending on body position, although conditions for fluid transfer may or may not be favourable at any particular area. The sinus pressure will be related more closely to right auricular pressure than to that of cerebral veins.

The fundamental structures allowing the transfer of cerebrospinal fluid from the subarachnoid space to the venous blood are tiny tubules referred to by Welch and Friedman (1960) as cerebrospinal fluid valves. They are described in monkeys as one-way
TABLE 2

EFFECT OF POSTURE ON CEREBROSPINAL FLUID PRESSURE (PATIENT LYING FACE UPWARDS)

\begin{tabular}{lc}
\hline Position & $\begin{array}{c}\text { Mean cerebrospinal fluid pressure at coronal suture } \\
\text { near superior sagittal sinus relative to atmospheric } \\
\text { pressure }\left(\mathrm{mm} \mathrm{H}_{2} \mathrm{O}\right)\end{array}$ \\
\hline $\begin{array}{l}\text { Horizontal } \\
\text { Body tilt } 25^{\circ}\end{array}$ & +12 \\
$\begin{array}{c}\text { (Head down) } \\
\text { Body tilt } 25^{\circ} \\
\text { (Head up) }\end{array}$ & +125 \\
\hline
\end{tabular}

valves formed from tubules $4 \mu$ to $12 \mu$ in diameter. These tubules in the arachnoid villi and granulations operate because of the pressure difference between $\mathscr{\Omega}$ the subarachnoid space and the venous sinus or $\$$ venous lacuna. Welch and Friedman (1960) studied $\vec{D}$ the flow-pressure characteristics of the arachnoid granulations in a piece of excised monkey dura $\vec{\omega}$ mater. The critical opening pressure was $60 \mathrm{~mm}$ of $\mathrm{H}_{2} \mathrm{O}$ (i.e., pressure difference across the membrane) and the flow-pressure relationship was as shown in Table 3. The venous lacunae and the superior sagittal sinus possess rigid walls and are therefore ideal as suction pumps.

TA BLE 3

RELATIONSHIP BETWEEN FLOW RATE AND PRESSURE ARACHNOID TUBULES OF MONKEY DURA MATER

\begin{tabular}{cc}
$\begin{array}{c}\text { Pressure of perfusion fluid } \\
(\mathrm{mm} \text { of water })\end{array}$ & $\begin{array}{c}\text { Flow } \\
\left(\mathrm{mm}^{3} \text { per } \mathrm{min}\right)\end{array}$ \\
\hline 60 & opening pressure \\
100 & 3 \\
150 & 11 \\
200 & 19 \\
250 & 31 \\
\hline
\end{tabular}

Remarks on the pressure in the superior sagittal sinus and in the lacunae laterales (venous lacunae) One may compare the venous lacunae and the superior sagittal sinus to the conditions existing in the use of the Pitot tube. The latter is a velocity measuring instrument and a differential pressure generating $\dot{0}$ device. It consists of a small tube sealed at one end and adjacent to this sealed end a small hole is drilled $\delta$ in the tube wall. The tube is inserted in the fluid being measured with the orifice pointing upstream 0 (Fig. 8). On impinging upon the Pitot tube, the $D$ forward motion of the fluid is arrested, and an excess head is generated in the tube equal to the kinetic energy. If a static pressure opening is made in the wall of the pipe there will be a pressure difference $N$ between this and the Pitot tube proportional to the N square of the velocity of the fluid. This seems a more 0 

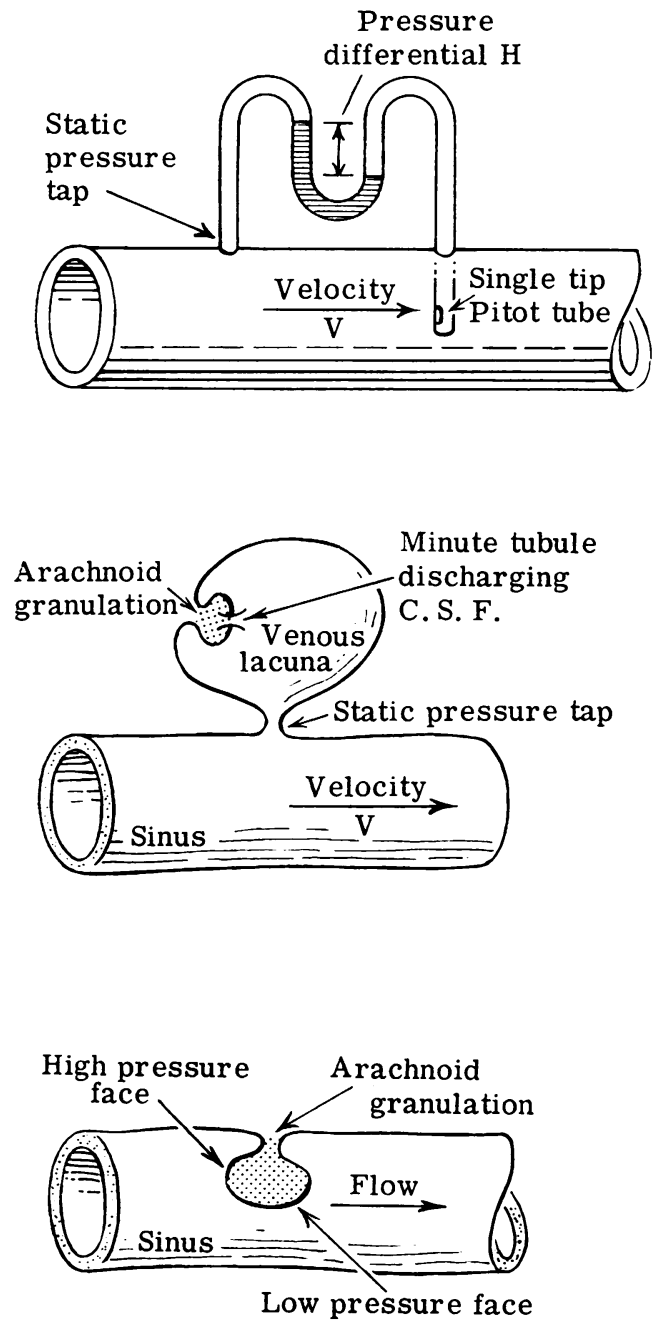

FIG. 8. Diagrams to illustrate the principle of the Pitot tube and the varying pressure states in relationship to flow and position in the cross section of a tube such as the superior sagittal sinus.

efficient arrangement than an arachnoid granulation sitting in the main stream of the superior sagittal sinus venous flow. The pressure in a lacuna resisting the outflow from an arachnoid valve will be lower than that present in the superior sagittal sinus. The pressure in this lake will fluctuate in response to pressure changes in the superior sagittal sinus and will discharge more easily into the sinus when the velocity in the sinus is high, since the lateral pressure as measured by a 'static' tap in the sinus wall will be low. When the flow is arrested in the superior sagittal sinus the pressure in the lacunae will equal the venous pressure and this may be higher than the opening pressure of the valves in the arachnoid granulations.

The rate of flow in a tubule for a given fluid depends on the coefficient of friction in the wall, the diameter, the length, and the pressure differential between the ends of the tubule. Nerve fibres have been traced to the granulations and lie in the vicinity of the tubules. Whether there is a mechanism for actively varying the tubule diameter does not appear to have been established.

The rate of cerebrospinal fuid production and absorption Heisey, Held, and Pappenheimer (1962) performed ventriculocisternal perfusions on chronically prepared unanaesthetized goats. Measurements were made of steady-state rates at which various substances including inulin and labelled water were removed from the perfusion fluid. The average value of cerebrospinal fluid production in the goat was $0 \cdot 16 \mathrm{ml} . / \mathrm{min}$. Rubin, Ommaya, Henderson, Bering, and Rall (1966) and Cutler et al. (1968) have provided important information in man - both on adults and children. They used perfusion techniques with careful flow rate and pressure control of fluids containing radioactive substances. If the total volume of cerebrospinal fluid in adult man is $140 \mathrm{ml}$. and the percentage rate of secretion per minute is 0.37 (Tubiana, Benda, and Constans, 1951) then the volume secreted per minute is $\frac{140 \times \cdot 37}{100}=0.5 \mathrm{ml}$. (approximately). This is equivalent to one large drop of fluid in every six seconds or over $700 \mathrm{ml}$. per 24 hours. In the goat, the rate of secretion is about one drop of fluid every 12 seconds, or more than $200 \mathrm{ml}$. per 24 hours.

It seems unnecessary to invoke a mechanism for cerebrospinal fluid circulation, since it is probable that fluid in the basal cisterns moves towards the vertex with a velocity of a small fraction of a millimetre per second. Tourtellotte (1968) concluded as follows: 'Evidence also suggests that in the subarachnoid space there is no flow of fluid in the conventional sense since substances merely move to the nearest point for absorption at the time of respiration variations in volume.' One cannot say that the drops of fluid exuding from the choroid plexus will be the 'same drops' which enter the venous sinuses. It is likely that water can reach the cerebrospinal fluid by a process of direct diffusion without having to pass through the choroid plexus. One would expect movement of water from the cerebrospinal fluid into the blood (apart from the venous sinuses) at the same rate as movement in the opposite direction. 


\section{DISCUSSION}

The introduction of sensitive pressure transducers has provided a method for precise measurements of fluid prossures in various intracranial areas and in the spinal subarachnoid spaces. This has demonstrated the remarkable variability of the pressure and the effects of factors such as posture, cardiac pulsation, respiration, etc. No such precise measurements have been made of pressures in the superior sagittal sinus and some of those which have been made have not indicated clearly the location of the sampling site.

It is important to realize that in a stream of fluid flowing in a tube the pressure varies in the cross section from the centre to the periphery. Also pressures recorded from a lateral tap will be lower than those in the centre of the flow and facing upstream. This latter pressure will be higher than that of a test with a tube opening downstream. This is relevant to any discussion of fluid transfer from the subarachnoid space or even from the venous lacunae to the superior sagittal sinus. The sinus with its connection to the right atrium of the heart is the inlet pipe of a suction pump which is fed fluid from three structures: the minute tubules of the arachnoid granulations projecting directly into the sinus, the slit-like openings of the entrances of the cerebral veins, and, thirdly, the variable side openings from the venous lacunae. The pressure differential between the two ends of the tubules in the arachnoid granulations sufficient to allow the flow of cerebrospinal fluid may be quite low, possibly of the order of $60 \mathrm{~mm}$ water pressure. If flow were to take place at all times via the arachnoid granulations in the vertex region, then the following conditions would be required.

In the supine position the cerebrospinal fluid pressure in this region would usually fluctuate around $100 \mathrm{~mm} \mathrm{H}_{2} \mathrm{O}$ pressure above atmospheric and the adjacent sinus pressure at the outlet end of an arachnoid tubule or the entrance of a venous lacunae would be less, perhaps $40 \mathrm{~mm} \mathrm{H}_{2} \mathrm{O}$ pressure. In the erect position, the cerebrospinal fluid pressure at the vertex is subatmospheric and the sinus pressure if cerebrospinal fluid transfer is to occur must be at an even lower pressure. The circulation of the cerebrospinal fluid is better described as a gentle ebb and flow related especially to the respiratory and cardiac pulses. Although the total volume of cerebrospinal fluid is changed several times in 24 hours it would only be necessary to absorb 10 drops of fluid per minute via the arachnoid granulations to balance the rate of production of cerebrospinal fluid. As mentioned previously this would not require a 'circulation' but a diffusion.

One reason for commencing the present study was an attempt to find abnormal pressure tracings in patients with presenile dementia and enlargement of the ventricles. This, so far, has given disappointing results, in that almost all such patients tested showed pressure recordings similar to those of normal patients. In one such patient, however, the oscillation of the pressure curve measured at the foramen of Monro was consistently $80 \mathrm{~mm}$ water pressure, whereas the variation in normal subjects was up to $50 \mathrm{~mm}$ water pressure. One wondered whether this increased pulse wave was a factor in ventricular dilatation. Another patient with presenile dementia and dilated ventricles gave a normal pressure recording from the lateral ventricle when lying horizontally but in the sitting up position the fluid pressure at the vertex near the superior sagittal sinus became negative (which is the usual finding). However, the extent of this pressure drop was surprising, the pressure being of the order of $-180 \mathrm{~mm}$ of water compared with atmospheric pressure. One may wonder whether cerebrospinal fluid absorption can occur into the superior sagittal sinus in such a patient in the erect position. Whatever may be the various factors responsible for the occurrence of dilatation of the ventricles in association with presenile dementia, there are many sub jects in whom no abnormality of fluid pressures can $b \stackrel{\infty}{\infty} \omega$ detected. In these patients there appears to be $Q$ 'mechanical failure' of cerebral tissue which is unable to resist normal stresses. Dilatation of the ventricles in other patients may be due to an increased amplis tude of the pressure wave, although the maximugu cerebrospinal fluid pressure is not significant $\overrightarrow{\vec{\omega}}$ elevated. In some cases there appears to be a large change of pressure with posture, so much so that in the erect position the cerebrospinal fluid pressure at the vertex may be almost $200 \mathrm{~mm}$ water below atmospheric pressure.

Whether this may be a factor in delaying fluid transfer to the venous sinuses is not clear. Further studies are necessary and valuable information is being collected from investigations with radioactive substances. It is possible that, in certain cases where ventricular dilatation has occurred, variations in production and absorption of cerebrospinal fluid may be correlated with abnormal recordings of fluid pressures.

I would like to express my appreciation to Miss Joan Thomas, Dr. Max Griffith, Dr. R. Rippert, and Mr. A. Bratspies for their valuable assistance.

\section{REFERENCES}

Clarke, W. E. Le G. (1920). On the pacchionian bodies. J. Anat. (Lond.), 55, 40-48.

Cutler, R. W. P., Page, L., Galicich, J., and Watters, G. V. O (1968). Formation and absorption of cerebrospinal $\omega$ fluid in man. Brain, 91, 707-720. 
Davson, H. (1967). The Physiology of the Cerebrospinal Fluid. J. \& A. Churchill: London.

Dunbar, H. S., Guthrie, T. C., and Karpell, B. (1966). A study of the cerebrospinal fluid pulse wave. Arch. Neurol. (Chic.), 14, 624-630.

Falkenheim, H., and Naunyn, B. (1887). Ueber Hirndruck. Arch. exp. Path. Pharmakol, 22, 261-305.

Gilland, O. (1969). The undistorted physiological cerebrospinal fluid pressure. In 4th International Congress of Neurological Surgery, and 9 th International Congress of Neurology. Abstracts of Papers, edited by C. G. Drake and R. Davoisin. p. 221. Amsterdam, Excerpta Medica (International Congress Series, No. 193).

Goldensohn, E. S., Whitehead, R. W., Parry, T. M., Spencer, J. N., Grover, R. F., and Draper, W. B. (1951). Studies on diffusion respiration. IX. Effect of diffusion respiration and high concentrations of $\mathrm{CO}_{2}$ on cerebrospinal fluid pressure of anesthetized dogs. Amer. J. Physiol., 165, 334-340.

Heisey, S. R., Held, D., and Pappenheimer, J. R. (1962). Bulk flow and diffusion in the cerebrospinal fluid system of the goat. Amer. J. Physiol., 203, 775-781.

Masserman, J. H. (1934). Cerebrospinal hydrodynamics. IV. Clinical experimental studies. Arch. Neurol.Psychiat. (Chic.), 32, 523-553.

O'Connell, J. E. A. (1943). The vascular factor in intracranial pressure and the maintenance of the cerebrospinal fluid circulation. Brain, 66, 204-228.

Rubin, R. C., Ommaya, A. K., Henderson, E. S., Bering, E.
A., and Rall, D. P. (1966). Cerebrospinal fluid perfusion for central nervous system neoplasms. Neurology (Minneap.), 16, 680-692.

Spina-Franca, A. (1963). (Quoted by Davson.) Variacoes fisiologicas da pressao do liquido cefalorraqueano na cisterna magna. Arch. Neuro-psiquiat. (S. Paulo), 21, 19-24.

Thomas, R. L., and Kerr, F. W. L. (1965). Electron microscopic studies of absorption of colloidal gold from the subarachnoid space. Mayo Clin. Proc., 40, 603-608.

Tourtellotte, W. W. (1968). In Pathology of the Nervous System, I, pp. 434-456. Edited by J. Mickler. McGrawHill Book Co.: New York.

Tubiana, M., Benda, P., and Constans, J. (1951). Sodium radio-actif ${ }^{24} \mathrm{Na}$ et liquide céphalo-rachidien: applications au diagnostic des méningites tuberculeuses et des compressions médullaires. Rev. neurol., 85, 17-35.

Weed, L. H. (1914-1915). Studies on cerebrospinal fluid. No. 111. The pathways of escape from the subarachnoid spaces with particular reference to the arachnoid villi. J. med. Res., 31, 51-117.

Weed, L. H., Flexner, L. B., and Clark, J. H. (1932). The effect of dislocation of the cerebrospinal fluid upon its pressure. Amer. J. Physiol., 100, 246-261.

Welch, K., and Friedman, V. (1960). The cerebrospinal fluid valves. Brain, 83, 454-469.

Wright, R. D. (1937-1938). Experimental observations on increased intracranial pressure. Aust. N.Z.J. Surg., 7, 215-235. 